\title{
Pharmaceutical Development of Immunomodulation and Effective Capsules for Application in the Rehabilitation Period of Sports of Higher Purposes
}

\author{
Shpychak OS ${ }^{1 *}$, Bobro SG ${ }^{2}$, Konovalenko IS ${ }^{2}$ and Shpychak $\mathbf{A O}^{3}$ \\ ${ }^{1}$ Doctor of Pharmacy, Professor of the Drug Technology Department, National University of Pharmacy, Kharkiv, Ukraine \\ ${ }^{2}$ Associate professor of the Department of Technology of Perfumes and Cosmetics, National University of Pharmacy, Kharkiv, Ukraine \\ ${ }^{3}$ Student of $4^{\text {th }}$ Grade, Specialty "Pharmacy", National University of Pharmacy, Kharkiv, Ukraine \\ *Corresponding Author: Shpychak OS, Doctor of Pharmacy, Professor of the Drug Technology Department, National University of \\ Pharmacy, Kharkiv, Ukraine.
}

Received: March 20, 2019; Published: May 02, 2019

DOI: $10.31080 /$ ASPS.2019.03.0270

\begin{abstract}
The expansion of the range of combined medicinal products of plant (natural) origin with a mainly sedative effect, which are shown for use in the treatment and prophylactic mode with overloading of the central nervous system and neuromuscular apparatus, muscular convulsions, rheumatism, autonomic neurosis, nerve excitations and depression are an actual problem of modern medical science and practice and sports medicine.

The aim of the study the presentation of the sequence of the contents of the pharmaceutical development of the complex apyphytodrug "Apised ${ }^{\circledR "}$ in the form of capsules on the basis of a standardized powdered honey substance (Specefications U 10.839834691-001: 2015) and medicinal plant material (herbs of medicinal lemon balm, inflorescences of lavender of the pericarp) for the treatment of stress conditions and nerve disorders of the central nervous system during the rehabilitation period of the athletes for compliance with the requirements of the standard "ST-N MOZ Ukraine regulation 42-3.0: 2011. Medicines. Pharmaceutical Development (ICH Q8)".

Hold the event the patterns of the effect of the pharmacological and technological factors affecting the basic stages of the technological process that are able to predict and scientifically substantiate the rational technology of the developed apyphyto drug for the complex treatment of sports injuries and nerve disorders in the period of the rehabilitation of athletes and the restoration of their capacity after the aftermath have been theoretically substantiated and experimentally confirmed.

Keywords: Pharmaceutical Development; Composition; Technology; Quality Control; Capsules; Apyphytodrug "Apised ${ }^{\circledR ” . ~}$
\end{abstract}

\section{Introduction}

In modern conditions there is a constant increase in the level of psychopathological disorders, in particular various neurotic disorders. The overwhelming clinical symptoms of these conditions are mostly expressed in the form of increased fatigue, reduced work capacity, irritability, tension, anxiety, depressed mood, loss of habitual interests, unmotivated fears, sleep disorders, etc., in this connection, pharmacotherapy for nerve disorders should be directed to eliminate manifestations of psychopathological disorders in accordance with the nature of their clinical picture [1].
To date, traditional and sports medicine for the treatment of this pathology most commonly used tranquilizers and antidepressants in significant doses, which in most cases suppress the central nervous system, weaken the adaptive processes in the body and have an unwanted side effect [2].

An alternative direction of pharmacotherapy for nerve disorders is the application in clinical practice of herbal medicines in combination with standardized substances of bee products that, unlike sedative synthetic drugs and classical tranquilizers, do not pose a hazard associated with the development of addiction, psy- 
chological and physical dependence [1,2]. In addition, herbal preparations and apiopods are widely used in modern sports medicine at all stages of training for athletes, both for increasing adaptation to loads, and for the treatment of pathological conditions. They practically do not change normal functions of an organism, do not show side effects and at the same time they are not toxic and doping substances $[3,4]$.

Unlike synthetic drugs, phytopreparations act more mildly and are better tolerated by patients. Advantages of herbal medicines are their ability to increase the adaptive capacity of the body in extreme conditions and the absence of the effect of the doping effect, which thereby expands their spectrum of pharmacological action and the possibility of use in sports medicine to accelerate the restoration of body functions of athletes due to overwork and overtraining [5].

In this connection, the expansion of the range of combined medicinal products of plant (natural) origin with a mainly sedative effect, which are shown for use in the treatment and prophylactic mode with overloading of the central nervous system and neuromuscular apparatus, muscular convulsions, rheumatism, autonomic neurosis, nerve excitations and depression are an actual problem of modern medical science and practice and sports medicine.

\section{The Aim of the Study}

The presentation of the sequence of the contents of the pharmaceutical development of the complex apyphyto drug "Apised ${ }^{\circledR "}$ in the form of capsules on the basis of a standardized powdered honey substance (Specefications U 10.8-39834691-001: 2015) and medicinal plant material (herbs of medicinal lemon balm, inflorescences of lavender of the pericarp) for the treatment of stress conditions and nerve disorders of the central nervous system during the rehabilitation period of the athletes for compliance with the requirements of the standard "ST-N MOZ Ukraine regulation 423.0: 2011. Medicines. Pharmaceutical Development (ICH Q8)" [6].

\section{Materials and Methodology}

In order to achieve this goal, organoleptic (appearance, color, taste, smell), pharmaco-technological (specific mass, volume and bulk density, fluidity, angle of natural slope, specific surface area and average particle size, humidity, etc.) were used in the work. Physical-chemical (loss in mass during drying, definition of consumer characteristics), microbiological (microbiological purity, antimicrobial activity), biological (specific pharmacological activity and harmlessness of the developed preparation), mathematical (statistical processing of data) and graphic research methods that allow to objectively evaluate the qualitative and quantitative indicators of the developed drug based on the results of experimental studies.

\section{Results and Discussion}

The substantiation of the composition of the active pharmaceutical ingredients (AFI) of LRS and MP and their correlation in the mixture was carried out in conjunction with the pharmacologists of the CNDL of NPAU taking into account the data of literary sources. In this case, the ratio of the substance MP: MPM was determined at the level of 40:60.

An important task in developing the technology of phytochemicals is the study of the basic technological parameters of RL. In this regard, we have conducted tests for shredded powders with RHCs and their mixtures according to the procedures outlined in the SPF [7]. Vegetable raw materials were pre-grounded using a rotary mill produced by the Spetstehotechnology plant (Kharkiv) to a degree of dispersion of $0.12 \pm 0.02 \mathrm{~mm}$. The residual powder that did not pass through the sieve No. 46 should not exceed $10 \%$. The main technological parameters of RHC and its mixtures, which are part of the drug Apised, are given in Table 1, the results of which indicate that the bulk of plant material after shrinkage decreases in 1.46-1.58 times, indicating the expediency of sealing the plant material when filling capsules. The results of the conducted experiment were used to further substantiate the composition and development of the industrial technology of the complex apyphytodrug under the conventional name "Apised" [8].

In order to substantiate the qualitative composition and quantitative content of auxiliary substances, the technological characteristics of the mixture of MPs with crushed LRC were investigated. According to the results of the studies, it was found that without the addition of additional substances, it is impossible to obtain a mass for encapsulation with satisfactory flow characteristics and their ability to shrink. In this regard, the following anti-friction substances were added to the mixture of active substances to improve its fluidity: talc, starch, Plasdone K29/32, as well as calcium stearate and aerosil in the amount of $0.5-2.0 \%$ (Table 2).

The results are presented in the table 2 , indicate that in order to improve the fluidity of the mixture of active ingredients, the addition of aerosil or a mixture of calcium stearate $(3: 1)$ in the amount of $2 \%$ is most appropriate. However, despite the results obtained, a cumulative analysis of the findings suggests the need to find more cardinal techniques. 
Pharmaceutical Development of Immunomodulation and Effective Capsules for Application in the Rehabilitation Period of Sports of Higher Purposes

\begin{tabular}{|c|c|c|c|c|}
\hline Technological parameters & Grass melisis & Cones hops & $\begin{array}{c}\text { Inflorescence } \\
\text { lavender }\end{array}$ & Mix \\
\hline Humidity, \% & $7,586 \pm 0,026$ & $5,930 \pm 0,015$ & $7,968 \pm 0,022$ & $6,814 \pm 0,036$ \\
\hline Fluidity, c/100 г & $81,14 \pm 2,87$ & $108,50 \pm 20,11$ & $111,86 \pm 20,95$ & $92,40 \pm 0,65$ \\
\hline The angle of natural slope & $43-44$ & $52-53$ & $45-46$ & $57-58$ \\
\hline \multicolumn{5}{|l|}{ Bulk volume, ml } \\
\hline$V_{0}$ & $70,4 \pm 0,52$ & $90,3 \pm 0,56$ & $74,2 \pm 0,71$ & $97,00 \pm 0,88$ \\
\hline$V_{10}$ & $56,2 \pm 1,04$ & $72,7 \pm 0,83$ & $57,3 \pm 1,36$ & $78,4 \pm 1,89$ \\
\hline$V_{500}$ & $47,2 \pm 1,04$ & $63,6 \pm 1,42$ & $48,7 \pm 1,21$ & $69,6 \pm 1,42$ \\
\hline$V_{1250}$ & $46,2 \pm 1,04$ & $62,2 \pm 1,04$ & $47,2 \pm 1,04$ & $65,2 \pm 1,04$ \\
\hline$V_{2500}$ & $45,8 \pm 1,04$ & $61,8 \pm 1,04$ & $46,7 \pm 1,04$ & $63,2 \pm 1,04$ \\
\hline Specific mass, $\mathrm{g} / \mathrm{cm}^{3}$ & $1,3543 \pm 0,0040$ & $1,4790 \pm 0,0034$ & $1,3678 \pm 0,0020$ & $1,4119 \pm 0,0026$ \\
\hline Volumetric density, $\mathrm{g} / \mathrm{cm}^{3}$ & $0,6505 \pm 0,0059$ & $0,7502 \pm 0,0060$ & $0,6634 \pm 0,0055$ & $0,7062 \pm 0,0057$ \\
\hline Bulk density, $\mathrm{g} / \mathrm{cm}^{3}$ & $0,3083 \pm 0,0018$ & $0,1910 \pm 0,0015$ & $0,2434 \pm 0,0025$ & $0,2189 \pm 0,0051$ \\
\hline Porosity of raw materials & $0,5197 \pm 0,0037$ & $0,4927 \pm 0,0045$ & $0,5150 \pm 0,0045$ & $0,4998 \pm 0,0035$ \\
\hline Cutting of the layer & $0,5261 \pm 0,0060$ & $0,7455 \pm 0,0022$ & $0,6330 \pm 0,0048$ & $0,6901 \pm 0,0074$ \\
\hline Free volume layer & $0,7724 \pm 0,0015$ & $0,8709 \pm 0,0012$ & $0,8220 \pm 0,0017$ & $0,8449 \pm 0,0037$ \\
\hline $\begin{array}{l}\text { Specific surface of particles, } \\
\mathrm{cm}^{2} / \mathrm{g}\end{array}$ & $613,79 \pm 5,58$ & $993,06 \pm 14,23$ & $777,33 \pm 8,97$ & $866,26 \pm 20,46$ \\
\hline Average particle size, $\mathrm{cm}$ & 0,02 & 0,02 & 0,02 & 0,02 \\
\hline
\end{tabular}

Table 1: Results of determination of basic technological parameters researched MPM and its mixture $(n=5, P=95 \%)$.

\begin{tabular}{|c|c|c|c|c|c|}
\hline Indicator & $\begin{array}{l}\text { API mix, talc } \\
\text { and starch }\end{array}$ & $\begin{array}{l}\text { API mix and } \\
2 \% \text { aerosol }\end{array}$ & $\begin{array}{c}\text { API mix, } \\
0,5 \% \text { calcium stea- } \\
\text { rate and } 1.5 \% \\
\text { aerosol }\end{array}$ & $\begin{array}{c}\text { API mix, } 2 \% \\
\text { calcium stearate }\end{array}$ & $\begin{array}{c}\text { API mix, } \\
\text { 5\% Plasdone K29/32 } \\
\text { and 1\% calcium stearate }\end{array}$ \\
\hline Fluidity, sec/100 g & $115,5 \pm 0,6$ & $25 \pm 2$ & $24 \pm 2$ & $33 \pm 2$ & $33 \pm 6$ \\
\hline The angle of natural slope, $\stackrel{o}{ }$ & $45-46$ & $35-36$ & $34-35$ & $38-39$ & $38-39$ \\
\hline Bulk volume $V_{0}, \mathrm{ml}$ & $378 \pm 2$ & $398 \pm 2$ & $394 \pm 2$ & $396 \pm 2$ & $381 \pm 2$ \\
\hline $\begin{array}{l}\text { Bulk volume after shrinkage } \\
V_{10}, \mathrm{ml}\end{array}$ & $265 \pm 2$ & $276 \pm 2$ & $275 \pm 2$ & $278 \pm 2$ & $273 \pm 2$ \\
\hline $\begin{array}{l}\text { Bulk volume after shrinkage } \\
V_{500}, \mathrm{ml}\end{array}$ & $234 \pm 2$ & $241 \pm 2$ & $240 \pm 2$ & $245 \pm 2$ & $239 \pm 2$ \\
\hline $\begin{array}{l}\text { Bulk volume after shrinkage } \\
V_{1250}, \mathrm{ml}\end{array}$ & $214 \pm 2$ & $221 \pm 2$ & $218 \pm 2$ & $218 \pm 2$ & $220 \pm 2$ \\
\hline $\begin{array}{l}\text { Ability to shrink } V_{10}-V_{500} \\
\mathrm{ml}\end{array}$ & 31 & 35 & 35 & 33 & 34 \\
\hline Bulk density $m / V_{0^{\prime}} \mathrm{g} / \mathrm{ml}$ & $0,265 \pm 0,002$ & $0,251 \pm 0,002$ & $0,254 \pm 0,002$ & $0,253 \pm 0,002$ & $0,262 \pm 0,002$ \\
\hline $\begin{array}{l}\text { Bulk density after shrinkage } \\
m / V_{1250}, \mathrm{~g} / \mathrm{ml}\end{array}$ & $0,467 \pm 0,002$ & $0,452 \pm 0,002$ & $0,459 \pm 0,002$ & $0,459 \pm 0,002$ & $0,455 \pm 0,002$ \\
\hline
\end{tabular}

Table 2: Pharmacological and technological characteristics of mass for encapsulation $(n=5, P=95 \%)$. 
In this regard, we were asked to conduct a preliminary granulation of a mixture of active substances. As a moisturizer, starch, PVP, Plasdone K29/32 and Plasdone S629 (in the form of 5\% solutions) were used (Figure 1).

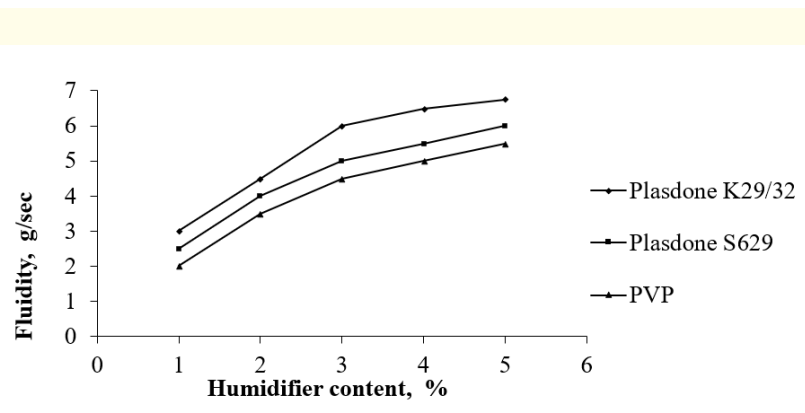

Figure 1: Dependence of mass flow rate for encapsulation on the content of humidifiers.

The results of the study of the fluidity of the resulting granulated masses for encapsulation (Figure 1) indicate that the best flow rates were observed when Plasdone K29/32 was used as a 5\% moisturizer. At the same time, the ability to shrinkage decreased and reached acceptable values. It should also be noted that the time of disintegration of granules at the same time did not exceed the permissible limits. The use of starch solution as a moisturizer led to the adhesion of the resulting granulate, which made it impossible to use it for the production of capsules "Apised".

The next stage of the research was the choice of optimal order of mixing and granulation of active and auxiliary substances. In the course of the experiment, different variants of mass obtaining for encapsulation were investigated. As a result of the studies, it was found that optimal pharmaco-technological parameters were obtained by applying a variant of preparation of mass for encapsulation in which a 5\% Plasdone K29/32 solution was added to the plant raw material mixture and granulation was performed, and then MP and anti-friction agent was added to the resulting granulate (aerosol). This version of the technology was used in the process of developing the technology of production capsules "Apised".

Thus, the complex of conducted pharmaco-technological studies allowed to substantiate the qualitative composition and the quantitative content of auxiliary substances in the mass for encapsulation in the manufacture of pharmaceutical and manufacturing in industrial conditions, developed by us capsules "Apised": aerosil - 2\%, Plasdone K29/32-5 \%, as well as the technology for obtaining mass for encapsulation. On the basis of our research, we have substantiated the composition of the apyphyto drug capsule - Apised [8,9]:

Composition of the apyphytodrug "Apised" per capsule, g:

Active Pharmaceutical Ingredients

Honey Powder (MP) or

Honey natural powdered (MNP) $\quad-0,100$

Medicinal Melissa grass - 0,045

Bumps of ordinary hops $-0,060$

Inflorescences of lavender of narrow-leafed - 0,040

Excipients

Silicon dioxide is colloidal anhydrous $-0,005$

Plasdone K29/32 (5 \% solution) - 0,013

Content of the components of one capsule $-0,263$

Based on the results of the physical, physico-chemical and pharmaco-technological investigations of AFI and their mixtures with auxiliary substances, we have developed a technology for obtaining capsules "Apised" by wet granulation.

The technological scheme of capsule production "Apised" is depicted in Figure 2.

The following indicators were used to standardize capsules "Apised" in accordance with the SPF: description, identification, average content of contents, homogeneity of contents, decomposition, dissolution, microbiological purity, quantitative determination.

With qualitative determination, the presence of flavonoids, phenol carboxylic acids and terpenoids is monitored by TLC, differential UV spectrophotometry and tandem chromatic-mass spectrometry (GC-MS-MS). Quantitative analysis is carried out using the HPLC method with the use of SZ quercetin, chlorogenic acid, linalolum, myrcenum, rosemary acid: the specification data used in the drafting of MCA on the proposed capsules.

The results of the study of stability of capsules "Apised" at their observation for 27 months allowed to determine the shelf life of 2 years when stored in a dry, dark place in the temperature range of $15-25^{\circ} \mathrm{C}$

The study of the sedative effect of capsules " Apised " and the preparation for comparing capsules "Phytosed" was conducted on the basis of the Central Research Laboratory of NUPh, under the direction of Dr. Pharmac. Sciences, prof. L.V. Yakovleva using the "open field" method using 40 white rats weighing 180-200 g. 


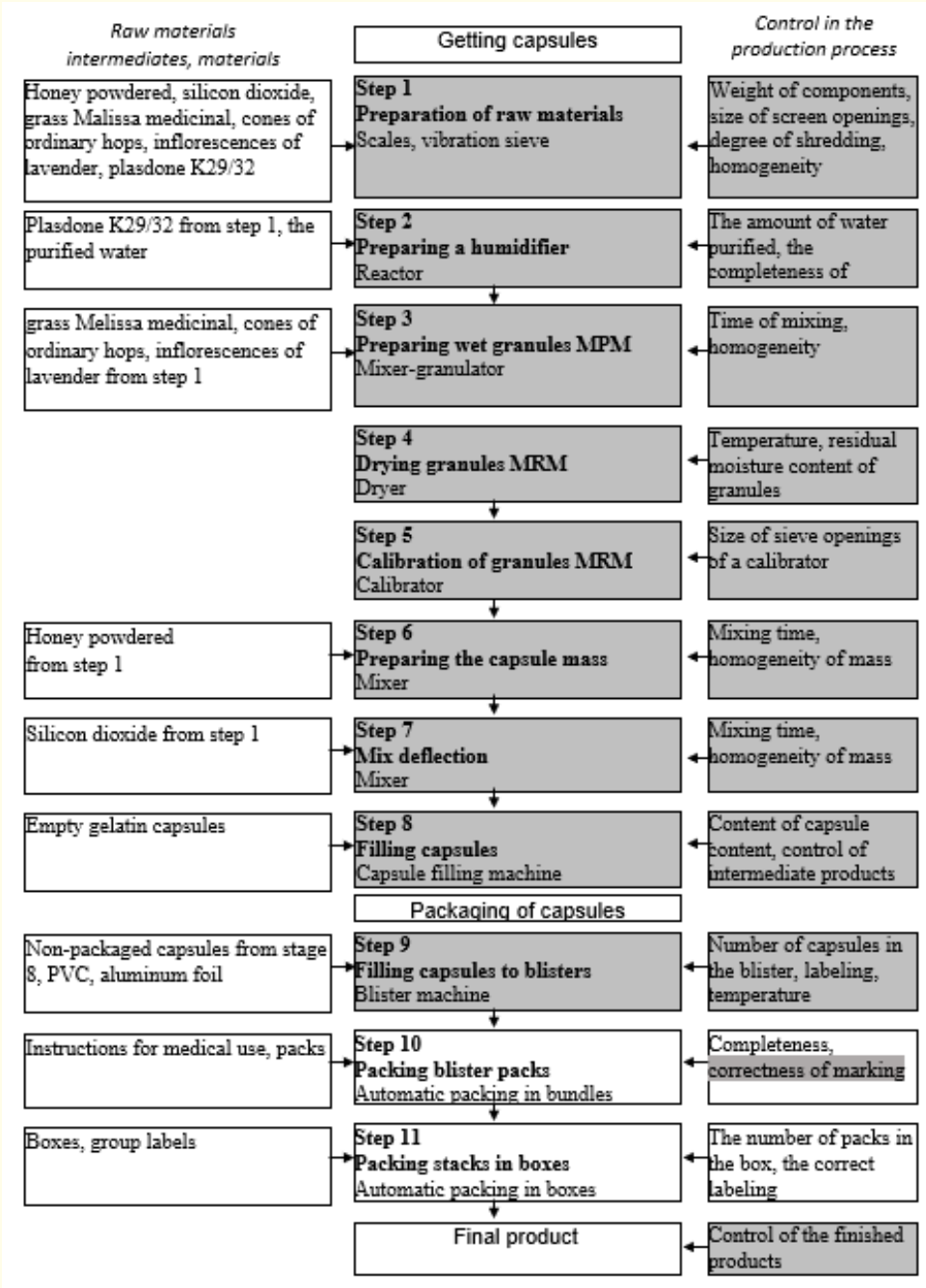

Figure 2: Block diagram of technological process of capsule production "Apised".

The results of the study show that capsules "Apised" exhibit pronounced sedative effect at a dose of $60 \mathrm{mg} / \mathrm{kg}$, which exceeds the sedative effect of the reference capsules "Phytosed" in a therapeutic dose of $108 \mathrm{mg} / \mathrm{kg}$ by $10 \%$.

Analysis of the results presented in Table 3 indicates that capsules "Apised" at a dose of $60 \mathrm{mg} / \mathrm{kg}$ are reliably comparable to the control group, while the "Phytosed" capsules at a dose of $108 \mathrm{mg} /$ $\mathrm{kg}$ tendentially lengthen the duration of medical sleep by 1.32 and 1.22 times respectively, indicating their ability to suppress the CNS activity by $32 \%$ and $23 \%$, respectively, and the advantage of a new apyphyto drug over the reference at $10 \%$.

\begin{tabular}{|l|c|c|c|}
\hline No & $\begin{array}{c}\text { Experimental } \\
\text { conditions }\end{array}$ & $\begin{array}{c}\text { Duration of } \\
\text { sleep, min }\end{array}$ & $\begin{array}{c}\text { Sedative } \\
\text { action, \% }\end{array}$ \\
\hline 1 & Control pathology & $\begin{array}{c}148,40 \pm \\
11,30\end{array}$ & - \\
\hline 2 & Capsules "Apised", 60 & $196,20 \pm$ & 32,20 \\
& mg/kg & $9,26^{*}$ & \\
\hline 3 & $\begin{array}{c}\text { Capsules "Phy- } \\
\text { tosed",108 mg/kg }\end{array}$ & $182,30 \pm$ & 22,84 \\
& \multicolumn{2}{|c|}{10,13} & \\
\hline
\end{tabular}

Table 3: Influence of the apyphyto drug "Apised" and the reference capsules "Phytosed" for the duration of the medication sleep.

Note: *The deviation of the indicator is reliably relative to the intact control group $(\mathrm{P} \leq 0,05)$ 
This activity of the new drug in this test convincingly testifies to the ability of capsules "Apised" to perform not only sedative, but also a weak hypnotic and anxiolytic effect, which is important for the treatment of physical and psychological overexcitement of the body and neurotic conditions. The results of the experiment also testify to the expediency of combining the aromatic herbal material with the standardized powdered honey substance, which has a stimulating effect on the synergism of the pharmacological action of the studied drug, in the composition of the apophytic preparation developed.

Conducted studies of the acute toxicity of capsules "Apised" revealed the absence of its toxic effects with single intragastric administration to male rats and female rats at a dose of $5000 \mathrm{mg} /$ $\mathrm{kg}$, which suggests that the median-lethal dose LD50 is beyond the dose administered to animals - $5000 \mathrm{mg} / \mathrm{kg}$ This allows us to conclude that according to the toxicological classification of substances K. K. Sidorov capsules "Apised" with intragastric introduction belong to the class $\mathrm{V}$ toxicity - virtually harmless substances [9].

\section{Conclusions}

- The sequence of contents of the pharmaceutical development of the apyphyto drug Apised $\AA$ in the form of capsules on the basis of the standardized substance of powdered honey and medicinal herbal raw materials for compliance with the requirements of the standard "Attitude ST-N of MOHU 42-3.0:2011. Medicines. Pharmaceutical development (ICH Q8)".

- The patterns of the effect of the pharmacological and technological factors affecting the basic stages of the technological process that are able to predict and scientifically substantiate the rational technology of the developed apyphyto drug for the complex treatment of sports injuries and nerve disorders in the period of the rehabilitation of athletes and the restoration of their capacity after the aftermath have been theoretically substantiated and experimentally confirmed.

\section{Bibliography}

1. Medical rehabilitation: manual for doctors/Edited by B. A. Epifanova. - 2nd edition, corrected and supplemented. - Moskov. : МЕДpress-inform, (2008): 352.

2. Gavrilova EA. Stressor immunodeficiency at athletes: a monograph Moskov, Sovetskiy sport (2009): 192.

3. Popova NV., et al. Medicinal Plants of the World Flora: An Encyclopedic Reference. - Лрфклшм: Dissa Plus, (2016) 540.
4. Tichonow ., et al. Miód naturalny w medycynie i farmacji (Pochodzenie, właściwości, zastosowanie, preparaty lecznicze) / Monografia pod redakcją akademika Ukraińskiej Akademii Nauk A. I. Tichonowa/Redaktor wydania polskiego: Prof. dr hab. n. farm. Bogdan Kędzia. - Stróże: Wydawca: "Sądecki Bartnik" (2017): 264.

5. Sports medicine: National leadership/S. P. Mironov, B. A. Polyaev, G. A. Makarova; ASMOK. - Moskov : GEOTAR-Media, (2012): 1184.

6. Instruction "ST-N MOZ Ukraine 42-3.0:2011". Medicines. Pharmaceutical Development (ICH Q8) (Official Edition)/M. O. Lyapunov, O. P. Bezuglaya, Yu. V. Podprugnikov et al. - K. : MOZ Ukraine (2011): 33.

7. Hryzodub OI. (ed.). Derzhavna Farmakopeya Ukrayiny [State Pharmacopoeia of Ukraine. State Enterprise "Scientificand-expert pharmacopoeial center"]. Derzhavne pidpryemstvo "Ukrayins'kiy naukoviy farmakopeyniy tsentr yakosti likars'kykh zasobiv", Kharkiv (in Ukrainian). ISBN 978-96697390-0-1 (2015)

8. Patent for invention № 105243, Ukraine, МПК51 А61К 9/48, A61K 35/64, A61K 36/18, А61K 36/53, A61P 25/20. Therapeutic and prophylactic means in the form of capsules with sedative effect/Shpychak O.S., Tykhonov O.I.- № a 201205332; 28.04.2012; 25.04.2014 8 (2012): 5.

9. Shpychak OS. The theoretical and experimental substantiation of the composition and development of the technology of apiphytomedicines for use in sports medicine. Kharkiv: Abstract on Dis. for the Degree of Dr. Pharm (2016): 45.

\section{Volume 3 Issue 6 June 2019}

\section{(C) All rights are reserved by Shpychak OS., et al.}

